\title{
Utility of Seed Germination Inhibition Test for Early Pregnancy Diagnosis in Buffaloes
}

\author{
V. Aswathnarayanappa, P.M. Gururaj", Nagappa Banuvalli and M. Harisha \\ Department of Veterinary Physiology and Biochemistry, Veterinary College, \\ Shivamogga-577204, Karnataka, India \\ *Corresponding author
}

\begin{tabular}{|l|}
\hline Key w or d s \\
Early pregnancy, \\
$\begin{array}{l}\text { Seed germination } \\
\text { inhibition }\end{array}$ \\
\hline Article Info \\
\hline $\begin{array}{l}\text { Accepted: } \\
\text { 12 May } 2019 \\
\text { Available Online: } \\
\text { 10 June } 2019\end{array}$ \\
\hline
\end{tabular}

\section{Introduction}

The establishment and maintenance of pregnancy result from complex interaction of the hormones and signalling by the conceptus after successful artificial insemination or

\begin{abstract}
A B S T R A C T
Early pregnancy diagnosis plays a key role for profitable and sustainable animal husbandry practices especially in the productive animal species like cattle and buffaloes. In this context, a study was undertaken to assess the utility of seed germination inhibition technique (Punyakoti test) for early detection of pregnancy in buffaloes. Thirty nondescript buffaloes were randomly selected from the different villages of Bangalore Rural district. The urine samples from selected buffaloes were collected while they were naturally micturating early in the morning on day 30,45 and 60 after artificial insemination and the samples were subjected to seed germination inhibition test within four to six hours of collection. Wheat, green gram and ragi seeds were subjected for germination after diluting the urine sample with distilled water in the ratio of 1:4. The per cent seed germination after 48 hours and the extent of shoot length on the fifth day were recorded. The pregnancy status of each test animal was confirmed per rectally on day 60 after artificial insemination. There was no significant difference $(P>0.05)$ in seed germination inhibition per cent on day 30 between inseminated buffaloes and confirmed non pregnant buffaloes. The germination inhibition per cent of the seeds of wheat, green gram and ragi among inseminated pregnant, inseminated non pregnant, confirmed non pregnant and distilled water control group differed significantly $(P<0.05)$ on day 45 and 60. There was no significant difference $(\mathrm{P}>0.05)$ in shoot length on day 30 between pregnant and non-pregnant buffaloes. However, the shoot length of all the seeds of wheat, green gram and ragi differed significantly $(P<0.05)$ in inseminated pregnant buffaloes compared to inseminated non pregnant, confirmed non pregnant and distilled control group on day 45 and 60 . Thus, from the present study, it was concluded that the seed germination inhibition test could be performed to detect early pregnancy in buffaloes.
\end{abstract}

natural mating. Early pregnancy diagnosis plays a key role for profitable and sustainable animal husbandry practices especially in the productive animal species like cattle and buffaloes. It would be undue extra feeding to the animals and extra burden to farmer 
thinking that they might be pregnant if they are not therefore, early and accurate pregnancy diagnosis is a key factor to shorten the calving interval (Sousa et al., 2006). One of the major limitations of improvements in buffalo production is their reproductive performance. The major constraints of buffalo reproduction are delayed maturity, silent heat, irregular estrous cycles, seasonal breeding, anoestrus and long calving intervals (Monndal et al., 2007 and Guraya, 1997). A number of pregnancy detection techniques have been established and practised ranging from simpler to complex one (Wani et al., 2003). The innovative test for pregnancy detection in women which was developed and inferred in the descriptions of ancient Egypt papyri was adopted with suitable modifications by Veena and Narendranath (1993). They had referred it as Punyakoti test which is also called as seed germination inhibition test or seed germination technique. Veena et al., (1997) observed that the extent of inhibition of the germination per cent and reduced shoot length of wheat seeds could be used as the bioassay for diagnosing pregnancy status in cattle/buffaloes. Generally, the techniques presently used such as rectal palpation, ultrasonography, assay of hormones and test for early pregnancy factors need trained, skilled personnel and also sophisticated laboratory equipments and procedures, which are beyond the reach of the farming community. In this direction, efforts towards the search of a new technique which is economical, easy to perform at the field level, for early detection of the pregnancy has been continued. One such method or technique, called as seed germination technique (Punyakoti test) was developed by Veena and Narendranath (1993) for cows based on the Egyptian method of pregnancy detection in women described in the Papyrii recovered by Flinders Peterie in 1898 during the excavation. Therefore, the present study aimed at assessing the utility of seed germination inhibition test to detect early pregnancy in buffaloes.

\section{Materials and Methods}

The seed germination inhibition technique to detect early pregnancy in buffaloes was performed as per the method described by Veena and Narendranath (1993). Ragi and green gram were procured from local market. The wheat seeds were procured from Dr. Sanjay Raja Ram Wheat Laboratory, All India Co-ordinated Wheat Improvement Project, Main Agricultural Research Station, The University of Agricultural Sciences, Dharwad. Thirty (30) non-descript buffaloes were randomly selected from the villages such of Devanahalli taluk of Bangalore rural District. The non-descript buffaloes considered for the present study had a good general body condition and all the animals were fed well and maintained under good managerial conditions. Among 30 animals identified, fifteen buffaloes were non pregnant that were not inseminated (Group I) that served as control group to compare the results of seed germination inhibition test. Remaining fifteen buffaloes were inseminated to serve as pregnant animals (Group II). A parallel test was also conducted with distilled water samples (Group III) to serve as one more control to compare the results. The fresh urine samples were collected in to clean dry containers while the buffaloes were naturally micturating early in the morning on day 30 , 45 and 60 of post insemination. The samples were immediately transported to the Laboratory of the Department of Veterinary Physiology, Veterinary College, Hebbal, Bangalore, wherein they were subjected to seed germination inhibition test within four to six hours of collection. For the each urine sample the seed germination inhibition test was conducted in triplicate for each seed selected for the study. In a series of petri dishes fifteen number of either wheat, or 
green gram or ragi seeds were placed, as the case may be. The urine sample of the test animal was diluted with distilled water in the ratio of 1:4. To each petri dish $15 \mathrm{ml}$ of diluted urine was added such that the seeds were sufficiently soaked in it. The petri dishes were covered with clean and dry trays to preserve moisture and also to avoid possible contamination and other disturbances. All the petri dishes were kept at room temperature away from sunlight and the observations were recorded for the per cent of seed germination inhibition in three types of seeds individually after 48 hours and the shoot length in centimeters in three types of seeds individually on fifth day of the test. A similar test was conducted with wheat seeds, green gram and ragi by using urine sample collected from non-pregnant buffaloes diluted with distilled water in the ratio of 1:4. Distilled water alone was also used to conduct a parallel control test in triplicate with three different types of seeds such as ragi, wheat and green gram. In each petri dish fifteen seeds were placed, the total number of seeds not germinated was counted after 48 hours. The germination inhibition per cent is calculated using the following formula as suggested by Narayana Swamy et al., (2010).

Total number of seeds not germinated Germination inhibition per cent $=$------ X 100

Total number of seeds taken in petri dish

Germination inhibition per cent was compared among confirmed non pregnant, non-inseminated buffaloes (Group II), inseminated pregnant buffaloes and inseminated non pregnant buffaloes (Group II), and with distilled water (Group III).

Shoot length of each seed was measured separately for wheat, green gram and ragi seeds. Shoot length among inseminated pregnant, inseminated non pregnant, confirmed non pregnant and distilled water were compared. The pregnancy status of each test animal was confirmed per rectally on day 60 of artificial insemination. The data was analyzed for statistical significance by using two way analysis of variance and the comparison between and within group of means were made by Tukey's post-test (GraphPad Prism software, Version 5.01, 2007)

\section{Results and Discussion}

On rectal examination after 60 days, six buffaloes were confirmed pregnant and nine were non pregnant out of 15 animals which were artificially inseminated. The average values of germination inhibition per cent of wheat seeds on day 30, 45 and 60 in the confirmed non pregnant Group (Group I), inseminated pregnant Group (Group II), inseminated non pregnant Group (Group II) and distilled water (Group III) were $39.56 \pm$ $0.99,38.52 \pm 0.93,40.50 \pm 1.27$ and $13.78 \pm$ $0.99,37.19 \pm 0.55,69.63 \pm 0.93,39.51 \pm 0.89$ and $13.63 \pm 1.26,41.04 \pm 0.86,65.19 \pm 0.93$, $38.27 \pm 0.89$ and $13.78 \pm 1.04$, respectively. The average values of germination inhibition per cent of Green Gram on day 30, 45, and 60 were $32.89 \pm 0.99,31.86 \pm 0.93,33.83 \pm 1.27$ and $6.81 \pm 0.90,29.93 \pm 0.77,65.56 \pm 0.95$, $33.34 \pm 0.74$ and $6.22 \pm 1.28,34.52 \pm 0.80$, $60.74 \pm 0.93,31.61 \pm 0.89$ and $6.519 \pm 1.15$, respectively. The average values of germination inhibition per cent of ragi on day 30,45 and 60 in the confirmed non pregnant Group (Group I), inseminated pregnant Group (Group II), inseminated non pregnant Group (Group II) and distilled water (Group III) were $61.78 \pm 0.99,61.11 \pm 1.25,62.72 \pm 1.27$ and $19.56 \pm 1.11,61.78 \pm 0.81,85.19 \pm 0.74$, $62.72 \pm 0.72$ and $19.71 \pm 1.05,63.41 \pm 0.80$, $82.97 \pm 0.93,60.50 \pm 0.89$ and $20.75 \pm 1.20$, respectively.

There was no significant difference $(\mathrm{P}>0.05)$ on day 30 between Group I, and Group II. 
However, the test with distilled water showed decreased germination inhibition per cent of wheat seeds on day 30 which was significant $(\mathrm{P}<0.05)$ compared to Group I and Group II.

It could be inferred that on day 30 , seed germination inhibition test is not useful for early pregnancy detection in buffaloes. The germination inhibition per cent of all the seeds differed significantly $(\mathrm{P}<0.05)$ within the Group II on day 45 and day 60 of post AI. Therefore, it was further confirmed that six buffaloes were pregnant and nine were non pregnant.
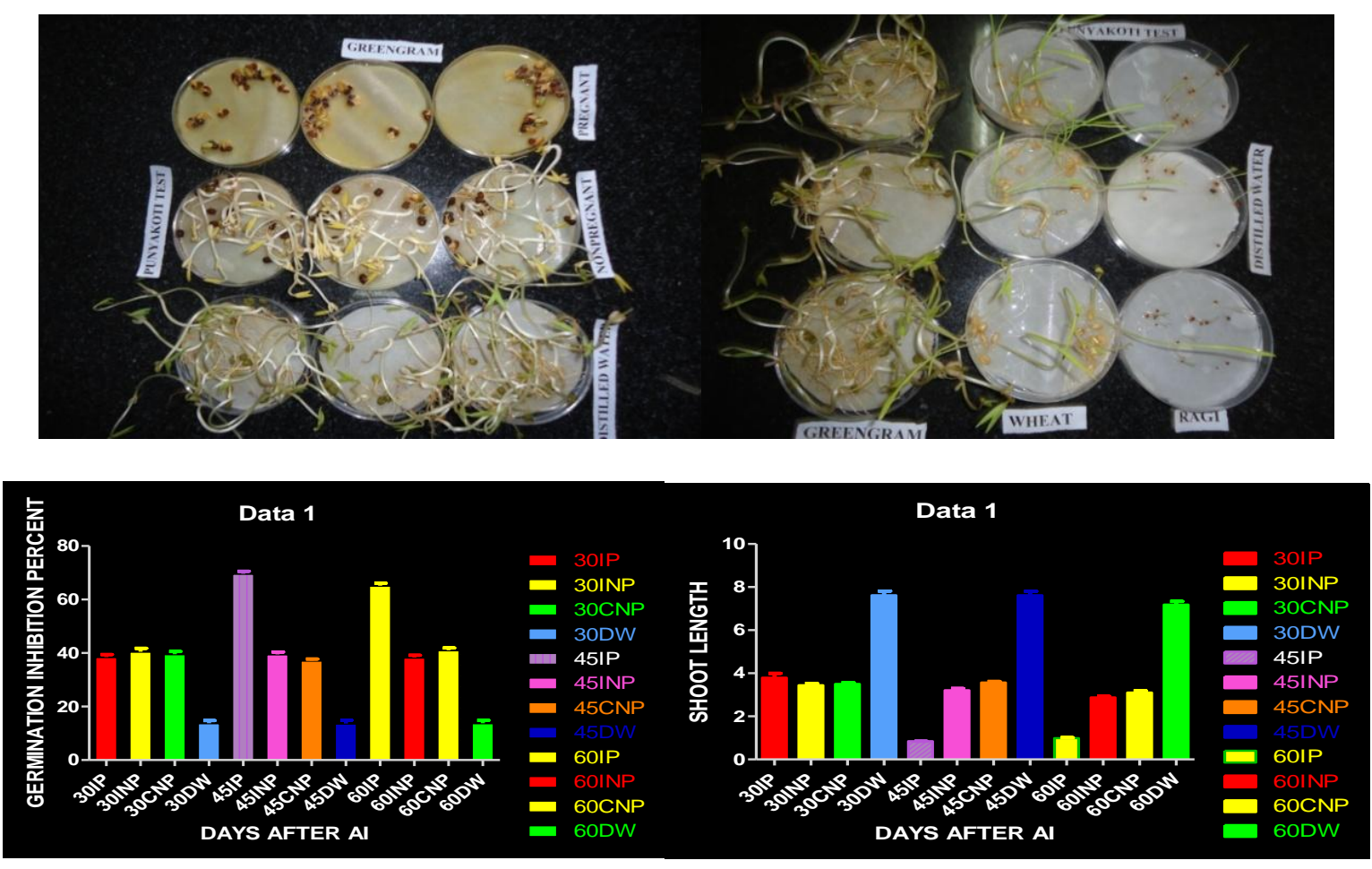

The average values of Shoot length of wheat seeds on day 30,45 and 60 in the confirmed non pregnant Group (Group I), inseminated pregnant Group (Group II), inseminated non pregnant Group (Group II) and distilled water (Group III) were $3.50 \pm 0.05,3.79 \pm 0.20$, $3.44 \pm 0.07$ and $7.61 \pm 0.19,3.56 \pm 0.05,0.84$ $\pm 0.00,3.21 \pm 0.07$ and $7.61 \pm 0.18,3.10 \pm$ $0.08,0.98 \pm 0.03,2.87 \pm 0.05$ and $7.19 \pm 0.14$, respectively. The average values of shoot length of green gram on day 30, 45 and 60 were $5.20 \pm 0.03,5.15 \pm 0.05,4.98 \pm 0.07$ and12.24 $\pm 0.23,4.83 \pm 0.10,1.30 \pm 0.05,4.67$ \pm 0.11 and $12.12 \pm 0.15,4.95 \pm 0.08,0.97 \pm$ $0.02, \quad 4.40 \pm 0.08$ and $12.08 \pm 0.11$, respectively. The average values of shoot length of ragi on day 30, 45 and 60 were 1.99 $\pm 0.02,1.95 \pm 0.04,1.94 \pm 0.09$ and $3.15 \pm$
$0.05,1.81 \pm 0.05,0.18 \pm 0.00,1.76 \pm 0.03$ and $3.12 \pm 0.07,1.92 \pm 0.06,0.24 \pm 0.00,1.84 \pm$ 0.01 and $3.11 \pm 0.07$, respectively. There was no significant difference $(\mathrm{P}>0.05)$ on day 30 between Group I, and Group II. The shoot length of all the seeds differed significantly $(\mathrm{P}<0.05)$ within the Group II on day 45 and day 60 of post AI.

The germination inhibition per cent of the seeds among inseminated pregnant, inseminated non pregnant and control non pregnant buffaloes group differed significantly $(\mathrm{P}<0.05)$. The present finding has shown that the seed germination inhibition by pregnant buffalo urine was more significant than that in non-pregnant buffalo urine. This was in agreement with the 
observation made by Veena and Narendranath (1993) in cattle, Veena et al., (1997) in cows, Shinde (1998) in cattle and buffaloes, Avahikar et al., (2002) in cows, Krishna Rao and Veena (2009) in cows and Yadav et al., (1999a) in does and Yadav et al., (1999b) in ewes. The findings in the present study were also in conformity with the findings of Dilrukshi and Perera (2009) in cattle and Narayana Swamy et al., (2010) in Malnad Gidda cows who noted a significant difference in seed germination inhibition using diluted pregnant cow urine samples. The degree of suppression of the shoot length in the seeds treated with diluted urine of the inseminated pregnant animals was more significant $(\mathrm{P}<0.05)$ than those treated with that of inseminated non pregnant animals. The present finding that suppression of wheat seed shoot growth by pregnant cow urine is more significant than in non-pregnant urine sample is in agreement with the observations of Veena and Narendranath (1993), Veena et al., (1997), Shinde (1998), Avahikar et al., (2002), Krishna Rao and Veena (2009) in cows. Similar findings were also observed by Yadav et al., (1999) in does and ewes, Dilrukshi and Perera (2009) and Narayana Swamy et al., (2010) in different breeds of cattle. Veena and Narendranath (1993) contemplated on the presence of identification of other inhibitory factor/s, if any.

They opined that the auxins and other plant growth regulators could be having effect on germination of seeds. The enhanced levels of such plant hormones in urine of cows during pregnancy might be responsible for inhibition of germination of wheat seeds. The inhibition of seed germination in the present study could be attributed to the increased levels of plant hormones as opined by Veena and Naredranath (1993). It can also be noted that Nirmala et al., (2008) opined that estrogen and progesterone hormones did not influence seed germination and shoot length.
Hence, concluded in the present study, it was evident from the results that the germination inhibition per cent was significant after 45 days post AI which has continued a similar trend even at $60^{\text {th }}$ day post AI. Thus, it was concluded that the inhibition of seed germination could be used as the parameter for the early pregnancy diagnosis after $45^{\text {th }}$ day post AI in buffaloes and the seed germination test is more useful in detecting pregnancy as it had no negative reactions for true pregnancy as well as for true non pregnancy.

\section{References}

Avahikar, G.T., Bapat, S.T., Markandeya, N.M. and Yeotikar, P.V., 2002. Cereal seed germination test for early pregnancy diagnosis in cow. $89^{\text {th }}$ Session of Indian Science Congress Association held between $3-7^{\text {th }}$ January, 2002 at Lucknow.

Dilrukshi, H.N.N, and Perera, A.N.F., 2009. Evaluation of An ancient technique to diagnose the pregnancy in cattle using urine. Wayamba Journal of Animal Science, 1: 6-8

Guraya, S.S., 1997. Ovarian biology in buffaloes and cattle. Edn. $1^{\text {st }}$. ICARNew Delhi. Pp: 1-6.

Krishna RAO, S. V., 2006. Seed Germination Technique (Punyakoti test) to detect early pregnancy in cows. M.V.Sc. thesis, Karnataka Veterinary, Animal and Fisheries Sciences University, Bidar, Karnataka, India

Krishna RAO, S. V., and Veena, T., 2009. Comparison of seed germination test with urine barium chloride test and milk copper sulphate test for efficacy to detect pregnancy in cows. Indian $J$. Anim. Res., 43(2): 124-126

Mondal, S., Prakash, B. S. and P. Palta., 2007. Endocrine Aspects of Oestrous Cycle in Buffaloes (Bubalus bubalis): An 
Overview. Asian-Aust. J. Anim. Sci., 20(1): $124-131$

Narayana Swamy, M., Ravikumar C. and Kalmath, G. P., 2010. Seed Germination inhibition test for pregnancy detection in Malnad Gidda Cows. Vet. World, 3(3):107-108

Nirmala, G.C., Veena, T., Jyothi, M.S and Suchitra, B. R., 2008. Effect of Estrogen and Progesterone on seed germination. Vet. World, 1(8): 241-242

Shinde, A.D., 1998. Laboratory methods of pregnancy diagnosis in cattle and buffalo. Dissertation submitted to Maharashtra Agricultural University, Parbhani.

Sousa, N. M., Ayad, A., Beckers, J. F. and Gajewski, Z., 2006. Pregnancyassociated glycoproteins (PAG) as pregnancy markers in the ruminants. $J$. Physio. Pharmacol., 57(8):153-171

Veena, T. and Narendranath, R., 1993. An ancient Egyptian pregnancy test extended to cattle. Curr. Sci., 65(1-2): 989-990.

Veena, T. AND Narendranath, R., 1997. Applicability of bioassay test for detection of early pregnancy - field trials. proceedings of XI Conference of Society of Animal Physiologists of India held at. National Institute of Animal Nutrition and Physiology, Audugodi, Bangalore during $24-26^{\text {th }}$ November 1997, pp: 83.

Wani, N. A., Shabeena Mustafa, Misra, A. K. and Maurya, S. N., 2003. Pregnancy diagnosis in farm animals - A review. Indian J. Dairy Sci., 56(1): 1-8

Yadav, C.D., Bapat, S.T. and Baawind, R.P., 1999b. A simple bioassay for pregnancy diagnosis in ewe. Pilot studies. Proceedings of $86^{\text {th }}$ session of Indian Science Congress-held at Chennai, $3^{\text {rd }}$ $7^{\text {th }}$ January, 1999.

\section{How to cite this article:}

Aswathnarayanappa, V., P.M. Gururaj, Nagappa Banuvalli and Harisha, M. 2019. Utility of Seed Germination Inhibition Test for Early Pregnancy Diagnosis in Buffaloes. Int.J.Curr.Microbiol.App.Sci. 8(06): 1453-1458. doi: https://doi.org/10.20546/ijcmas.2019.806.176 